\title{
'Heterowingka patriarcado del salario' en Desde el fogón de una casa de putas williche (2010) de Graciela Huinao. Una intersección de género, etnia, clase y raza
}

\section{'Heterowingka patriarchy of wages' in Desde el fogón de una casa de putas williche (2010) by Graciela Huinao. An intersection of gender, ethnicity, class and race}

\author{
ANÍBAL GABRIEL CARRASCO RODRÍGUEZ \\ ${ }^{a}$ Magíster en literatura chilena e hispanoamericana. Pontificia Universidad Católica de Valparaíso. \\ Correo electrónico: anibal_acr@hotmail.com
}

El presente artículo tiene como objetivo analizar la novela Desde el fogón de una casa de putas williche (2010) de Graciela Huinao desde un prisma interseccional de género, clase, etnia y raza. En esta obra se presenta un prostíbulo mapuche en un territorio fronterizo entre el mundo wingka y el mapuche, en este espacio las mujeres están a cargo de la administración, generando un lugar de relativa autonomía en medio de la violencia estatal y wingka que significó la ocupación de sus territorios. Nuestra hipótesis de lectura es que esta obra se puede leer en el marco de un entronque patriarcal, entre el patriarcado mapuche y el wingka. El entronque consolida, a través de la violencia, un 'heterowingka patriarcado del salario', frente al cual, el prostíbulo se establece como un espacio de oposición y subversión que desarticula la lógica patriarcal wingka y la mapuche.

Palabras claves: mapuche, wingka, intersección, subversión, oposición, patriarcado.

The aim of this article is to analyze Graciela Huinao's novel Desde el fogón de una casa de putas williche (2010) from an intersectional prism of gender, class, ethnicity and race. In this work a mapuche brothel is presented in a border territory between the wingka and the mapuche world, in this space the women are in charge of the administration, generating a place of relative autonomy in the middle of the state and wingka violence that meant the occupation of their territories. Our hypothesis of reading is that this work can be read in the context of a patriarchal junction, between the Mapuche patriarchy and the wingka. The junction consolidates, through violence a 'heterowingka patriarchy of salary', against which, the brothel is established as a space for opposition and subversion that disjoint the wingka and mapuche patriarchal logic.

Key words: mapuche, wingka, intersection, subversion, oposition, patriachy. 


\section{DESDE EL FOGÓN DE UNA CASA DE PUTAS WILLICHE: LA SEgUNDA NOVELA MAPUCHE}

Antes de adentrarnos en la novela y el análisis que hacemos de ella, daremos un breve recorrido por la obra y biografía de Graciela Huinao.

Dentro de la constelación de escritura de mujeres se encuentra Graciela Huinao (wili nawel: garra de tigre), poeta y narradora williche ${ }^{1}$ (o huilliche), quien nace el año 1956 en Chaurakawin (Osorno). Una de sus primeras apariciones fue un poema titulado "La Loika" el que fue publicado en 1980. Posteriormente parte de su obra poética fue publicada en 1998 dentro de una antología poética, a cargo de Cecilia Vicuña, titulada: $U$ Ul: Four Mapuche Poets (García Barrera, Carrasco Muñoz y Contreras Hauser 67). En 1988 la poeta llega a Santiago, donde vive la ignorancia de la capital respecto a la cultura Mapuche. En el 2001 Graciela Huinao publica el poemario Walinto, texto escrito en castellano y mapudungun, que está compuesto por 14 poemas. El año 2003 publica La nieta del brujo, seis relatos Williche. El año 2006 publicó una coedición de poesía llamada Hilando en la memoria, 7 mujeres poetas mapuche. Luego, en el año 2008, vuelve a publicar Walinto en una versión trilingüe (español-mapudungun-inglés). Durante el 2009 coeditó "Hilando en la memoria, ери rupa” 14 mujeres poetas mapuches. El año 2010 publicó su primera novela titulada Desde el fogón de una casa de putas Williche. Posteriormente en el año 2015 publica la novela Katrilef, hija de un ülmen williche.

Desde muy temprana edad Graciela Huinao viajó a Santiago en busca de oportunidades de trabajo, gran parte de su vida la desarrolló en la capital, frente a un clima hostil e indiferente a la cultura mapuche. Su obra expresa el dolor y complicaciones de una mujer mapuche que debe adecuarse al mundo urbano, abandonando el territorio que la vio nacer: "Hace tan sólo unos años, las mujeres mapuche nacíamos con un título bajo el brazo: Servicio Doméstico, y seguimos viviendo la misma situación” (Huinao en Falabella, Huinao y Rupailaf 103). Por esto su obra la podemos clasificar y comprender dentro de lo

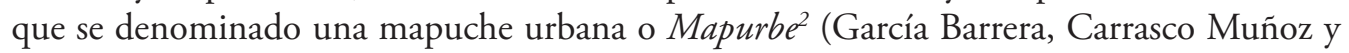
Contreras Hauser 73). Dentro de este contexto adverso para sostener su propia cultura, la escritora señala que siempre ha estado vinculada por un hilo invisible que se ha mantenido en su memoria, hilo que le permite una reafirmación cultural, señala sentirse parte del "polvo de estrellas". Uno de los aspectos que recorren de manera transversal su obra es la oralidad, siendo recurrentes las construcciones y referencias a la nostalgia, al país de la infancia, la reescritura de la historia mapuche, entre otras (García Barrera, Carrasco Muñoz y Contreras Hauser 68). También se ha relevado recientemente el poder y papel que tiene el

\footnotetext{
${ }^{1}$ Ella misma lo escribe de esa manera, respetamos en el texto su particular forma de escribir el mapudungun.

${ }^{2}$ Mapurbe es el nombre del poemario de David Aniñir, en él se ve un trabajo poético en torno a la vida mapuche en las periferias de Santiago. Muchas personas mapuche migraron del campo a las ciudades, en éstas debían sobrevivir al igual que muchas personas empobrecidas, resistiendo y luchando a través de toma de terrenos, siendo parte, en el caso de Santiago, de las llamadas poblaciones callampa. Véase Aniñir, David. Mapurbe, venganza a raíz. Santiago de Chile: Pehuén Editores, 2009.
} 
humor dentro de su escritura como un elemento vinculado a la forma de vida comunitaria y festiva. El humor también está presente en otras escrituras mapuche (Figueroa 92).

La novela Desde el fogón de una casa de putas williche ${ }^{3}$ (2010) se puede considerar la segunda novela escrito por una mapuche, sólo la precede Cherrufe. La bola de fuego (novela mapuche $)^{4}$ (2008), de Ruth Mariela Fuentealba Millaguir (1961, Nancul) (Carrasco 117). Leemos en Desde el Fogón... desde un prisma interseccional, debido a que nos permite revelar:

[Q]ue las desigualdades son producidas por las interacciones entre los sistemas de subordinación de género, orientación sexual, etnia, religión, origen nacional, (dis)capacidad y situación socio-económica, que se constituyen uno a otro dinámicamente en el tiempo y en el espacio (M. La Barbera 106).

Además, como se trata de un concepto que nace y es robustecido desde el feminismo, nos permite hilvanar la complejidad de la novela y el protagonismo de las mujeres ${ }^{5}$ en ella, lo que facilita ahondar en el trasfondo histórico-político de la obra. Tomando una perspectiva interseccional, señalamos que en la obra que examinamos se escenifica una transición entre un mundo mapuche-williche previo al resurgimiento de la acumulación originaria en Chile a través de la ocupación del territorio mapuche y otro posterior, en donde el mundo wingkachileno comienza a tener mayor influencia. Estos dos momentos tienen resonancias con el origen del prostíbulo que opera como escenario principal en la novela:

Cercana a cumplir veinticinco amargos años la reflejó el río, al mirarse en sus aguas. Estando en su orilla abrió el tarro, temblaron sus manos al empezar a contar. Un par de chauchas le sobraron al comprar el galpón. La idea de la casa de putas empezó a germinar dolorosamente, con el primer peso que el caminero le tiró en su cara de niña, después que la violó (76).

\footnotetext{
${ }^{3}$ De aquí en adelante abreviaremos el título a Desde el fogón... para no cansar a quien lea el artículo.

${ }^{4}$ En esta primera novela también son visibles elementos relacionados a la ocupación del territorio mapuche y la violencia histórica del Estado chileno y la de los colonos de diversa procedencia. Incluso el momento inicial de la novela que da movimiento a lo que continúa es la visión de Antonia, nińa protagonista, a quien le adviene un Peuma en el cual ve a un cacique siendo asesinado. Este sueńo termina siendo una suerte de premonición ya que su abuelo es golpeado y amenazado por un wingka que quiere comprarle las tierras. Frente a esta amenaza, la niña siente culpa por el Peuma que tuvo, se cree responsable de lo que le pasó a su abuelo (Millaguir 33). Constatamos así el vínculo estrecho entre las creaciones literarias mapuche y las demandas históricas de este pueblo.

${ }^{5}$ También se ha señalado que la idea o categoría de mujer se construye a través de los procesos de conquista y que, por lo tanto, deberíamos tomar esta noción con cuidado, así lo plantea Oyèrónkẹ Oyěwùmí. Sin embargo, adscribimos a ella y la utilizamos en el sentido de que se trata, en la novela, de una función o lugar móvil, no esencialista y que en la obra opera como categoría fundamental.
} 
En este sentido el prostíbulo se conforma como una respuesta frente a esta violencia patriarcal y va más allá de suplir meramente las necesidades económicas de las prostitutas, convirtiéndose en un espacio de relativa autonomía y alegría con respecto al contexto histórico en el que se sitúa la obra. De esta manera, las tres putas de planta del prostíbulo fueron: "más que un pilar sexual para el pueblo, el burdel era un gallinero donde los williche anidaban sus penas y alegrías; temores y valentías; donde una humillada lágrima se escondió debajo de la tierra pacificada" (102).

\section{LA ACUMULACIÓN ORIGINARIA COMO MATRIZ DE LECTURA}

La categoría de acumulación originaria nos parece pertinente como parte de la matriz de lectura de Desde el fogón... en la medida en que en ésta se narra una suerte de transición del mundo Mapuche previa a la Ocupación del Wallmapu/Araucanía y las consecuencias político-económicas que trajo consigo la implantación y consolidación del capitalismo.

Como Marx señaló, en la tercera parte del libro I de El Capital, para la transformación del dinero y de medios de producción en capital son necesario dos elementos previos y coincidentes: que surjan propietarios de los medios de subsistencia de un lado, y, por otro, personas "libres" "que puedan vender su fuerza de trabajo (Marx, El capital. Libro primero. El proceso de producción del capital 892). Marx define este proceso histórico de la siguiente manera:

La llamada acumulación originaria no es, por consiguiente, más que el proceso histórico de escisión entre productor y medios de producción. Aparece como "originaria" porque configura la prehistoria del capital y del modo de producción correspondiente al mismo (893).

Este momento inicial tendría sus especificidades locales, por lo que no se trata de un proceso clausurado, ni universal, ni lineal ${ }^{7}$. Se trata de un prisma de análisis del surgimiento de las condiciones necesarias para la explotación capitalista. De esta manera si bien Marx se focaliza en el proceso de Inglaterra, esto no quiere decir que las fases y elementos de ese proceso sean inmediatamente transportables al caso que examinamos. Sin embargo, si tomamos algunos de los elementos centrales y esenciales de este proceso, vemos que para el análisis de la novela son pertinentes:

\footnotetext{
${ }^{6}$ Aquí el adjetivo libre le sirve a Marx como una forma de dar cuenta de la particularidad del asalariado en el capitalismo. Dice: "libres en el doble de que ni están incluidos entre los medios de producción -como sí lo están los esclavos, siervos de la gleba, etcétera-, ni tampoco les pertenecen a ellos los medios de producción -a la inversa de lo que ocurre con el campesino que trabaja su propia tierra, etcétera-" (892-893).

${ }^{7}$ El mismo Marx señala que "La historia de esa expropiación adopta diversas tonalidades en distintos países y recorre en una sucesión diferente las diversas fases. Sólo en Inglaterra, y es por eso que tomamos de ejemplo a este país, dicha expropiación reviste su forma clásica" (Marx 895). Cabe notar que Marx se encontraba viviendo en Inglaterra mientras escribió El Capital, utilizando los informes y registros que tenía a mano.
} 
[L]os momentos en que se separa súbita y violentamente a grandes masas humanas de sus medios de subsistencia y de producción y se las arroja, en calidad de proletarios totalmente libres, al mercado de trabajo. La expropiación que despoja de la tierra al trabajador, constituye el fundamento de todo el proceso" (895).

Despojar a las personas de sus tierras, como elemento que les permitía la subsistencia y un vínculo comunitario sin acorralamiento, es una de las heridas que se encuentra presente en la novela, lo cual nos habla de la pertinencia conceptual de la noción de Marx:

su familia fue arrinconada por el estado chileno en la peor tierra y la mejor se la expropiaron a sus antepasados, para regalárselas a los desterrados que llegaron a colonizar un territorio que ya tenía dueño. A cambio, al nacer, como regalo del cielo le impusieron el bautizo, con la ilusión de heredar al morir un pedazo de tierra en el paraíso (39) ${ }^{8}$.

La usurpación de tierras y la destrucción del terreno comunitario afectó también los lugares sagrados, en los que se encuentran anudadas significaciones que los conectan con sus antepasados. En particular, en la novela se da cuenta del robo a los cementerios indígenas como otra expresión de la acumulación wingka: "De inmediato supo que ése era el llamado de su abuelo: el sagrado cementerio de su comunidad, dónde estaban sus ancestros había sido saqueado por los wingka" (29). El estrato natural es intervenido, destruyendo los ritos que se anudaban al territorio mapuche, así sucede con el río Rahue, el cual albergaba un desafío y una práctica constante de cruzarlo a nado: "Las nuevas autoridades para facilitar el despojo, habían apuñalado de lado a lado su respetado río con un kui-kui ${ }^{9}$ de madera; el antiguo desafío de bracearlo al amparo de la oración nativa se perdía ante el poder del dinero" (28).

La migración campo-ciudad ${ }^{10}$ posibilitada por la ocupación del territorio mapuche se encuentra ligada a formas coloniales de opresión y asimilación, así se explicita en la novela: "Fue la época del despojo (con el nombre de colonización se conoce hoy, la usurpación de

\footnotetext{
${ }^{8}$ Para ser precisos en la novela también se tejen algunos vínculos entre el pueblo Williche y los pueblos originarios del extremo sur. Una de las prostitutas llamada Culítica llora por ese pasado desgarrador de su cultura: "Mis abuelas loberas/ no tuvieron el derecho/ de morir en forma natural./ Fueron arreadas/ a una muerte violenta/ en medio de una codiciosa tempestad./ La misma tormenta/ atrapó mi canoa./ Mis viejas loberas lucharon/ lucharon por mi alma de niña/ hasta perderse en medio del mar." (95). El dolor de los pueblos del extremo sur también está atravesado por lo afanes comerciales y estatales de control territorial y soberanía.

${ }^{9}$ En la misma novela se señala a pie de página que se trata de "Un gran tronco de árbol atravesado sobre un río (Puente)" (28).

${ }^{10}$ En este proceso la ciudad es el bastión donde se resguarda y sostiene la forma occidental de vida. Fundar ciudades desde la conquista fue el medio para someter y demostrar el poder del Rey y de Dios frente al indígena de américa. Las ciudades se fundaron en un espacio que se concibió sin historia, sin cultura, imponiendo a través de la violencia el imperio de los signos (Guerra 21; Rama 36). Ciudades que se erigen como fuertes que poco a poco van acorralando y sometiendo, acortando las fronteras.
} 
tierra Williche avalada por el Estado). En este período, los Williche eran arreados como ganado por el camino, al destierro de la ciudad" (59). Este proceso los lleva a engrosar las filas de trabajadores 'libres' en busca de empleo para sostener una vida en los márgenes de las ciudades.

Al destruirse las formas de vida anterior, por la usurpación y destrucción de los lazos y medios de producción mapuche, se avala e incluso se promueve el trabajo infantil. Así se narra en la historia de Florencia Treukil Gonzáles (La Champurria), una de las prostitutas de "La Trompa de Pato": "siendo muy pequeña la vida la desafió a trabajar de niñera; cinco años contaba en su vida cuando empezó a ganar su propio pan” (31). En un comienzo, los alemanes para quienes trabajaba, sólo le pagaban con comida, cuando logró salir de aquel lugar, encontró otro trabajo doméstico a los 20 años luego de que: "había aprendido que el dinero es la ley que rige a los pueblos wingka" (31). Posteriormente, en su nuevo trabajo se sintió feliz de recibir un sueldo, de esta manera completó el tránsito hasta convertirse en una asalariada.

La relevancia de lo económico como amenaza a la cultura indígena queda explícita en la visión de la regenta del prostíbulo: "con el tiempo, más de un mapuche será un hombre acaudalado y el dinero es la base del poder en el nuevo Estado" (92). En base a esta misma necesidad de conseguir trabajo, muchas de las prostitutas llegan al cabaret al verse impelidas a trabajar, rompiendo el nexo con sus familias y su comunidad más extendida. Esto es lo que vemos en la trayectoria de la Pincoya y la Guatipota quienes dejaron de ver a sus familias cuando emprendieron ese viaje (88). Esta búsqueda de empleo asalariado, entre otros factores, decanta en la desarticulación de las comunidades mapuche. En esta misma línea Jimena Pichinao señala que la acumulación originaria puede concebirse como un proceso continuo y permanente que va sistemáticamente reforzando las relaciones capitalistas (91). Proceso de tensión y antagonismo que se extiende hasta la actualidad, pasando por la dictadura y los gobiernos posteriores, quienes han sostenido la continuidad de la acumulación.

\section{Patriarcado del salario y entronque patriarcal}

En la llamada acumulación originaria son las mujeres quienes se ven más afectadas por la destrucción de lo común, donde su rol era fundamental, por lo que quedan despojadas de sus funciones y desvalorizadas en términos de sus capacidades. Esto lleva a las mujeres desde el espacio público-comunitario al espacio doméstico marcado por la dominación patriarcal: "el grupo de trabajadores que, en la transición al capitalismo, más se acercaron a la condición de esclavos fueron las mujeres trabajadoras ${ }^{11}$ " (Federici 150). Esta

\footnotetext{
${ }^{11}$ En Calibán y la Bruja Federici señala que una vez avanzado el proceso de proletarización (en Europa) los hombres quedaron como nuevos señores feudales en donde los siervos eran las mujeres, incluso se llegó a criminalizar a las prostitutas, reforzando el poder de los trabajadores por sobre ellas. En el caso de América Latina, la autora señala que en Perú y México el proceso fue similar, la mujer fue obligada a seguir al marido a
} 
misma autora da cuenta del proceso de desmembramiento del lugar de la mujer indígena en América, proceso que, si bien se encuentra lejano al contexto más próximo de la novela, nos permite tener una visión histórica más extensa:

Antes de la conquista, las mujeres americanas tenían sus propias organizaciones, sus esferas de actividad reconocidas socialmente $y$, si bien no eran iguales a los hombres, se las consideraba complementarias a ellos en cuanto a su contribución a la familia y la sociedad (152).

Tal como vemos en Desde el fogón... una de las posibilidades para las mujeres dentro de este nuevo orden es casarse y depender del salario de un hombre o realizar trabajos domésticos en algún otro lugar, como en el caso de la Potoquina que es amenazada en el orfanato por una Superiora:

ella era indígena, su rol estaba sacramentado en saber cocinar y fregar pisos, experiencia que le serviría a futuro algún potentado pasara en su búsqueda y tras el pago de una buena suma de dinero, la convertiría en su flamante asesora de hogar: una esclava para toda la vida (99).

Para Federici hubo un giro en torno a la participación pública de las mujeres, ya que previa a la acumulación originaria ellas tenían injerencia en la toma de decisiones y en la organización de la vida social. Fedirici se detiene en señalar cómo la caza de brujas también recayó sobre las mujeres indígenas y en cómo, incluso, las técnicas de exterminio y sojuzgamiento utilizadas en las colonias fueron exportadas y replicadas en Europa, tratándose de un vínculo dialéctico y transoceánico (273). Si bien Federici examina con mayor profundidad los efectos en Europa de la acumulación originaria, seńalamos que estos en su mayor parte son correlativos a la cultura mapuche. Algunas investigaciones han sostenido que las mujeres tenían, antes de la Ocupación de la Wallmapu/Araucanía, un mayor peso e injerencia dentro de su comunidad. Uno de los saberes que utilizaban y aprendían las mujeres mapuche era el lawen ${ }^{12}$, el que estaba ligado al uso de la tierra común. Otra tarea fundamental, ligada a la crianza, era la transmisión cultural, en especial, del mapuzungun (Castillo y Rebolledo 10-11). Sin embargo, si bien las mujeres mapuches comparativamente tenían otra valoración y un lugar central, hay que destacar que esta particularidad cultural

donde sea que este fuese, transformándose en un apéndice de este, además, se le confinó al espacio doméstico y se le quitó la autoridad por sobre sus hijos e hijas (168). Ahora bien, la esclavitud propiamente tal existió en Chile, a pesar de que ha sido invisibilizada históricamente, agregando a este grupo humano, los escalafones se trastocan, porque la mujer negra aparece cargando toda la pirámide de la pigmentocracia sobre sus cuerpos. Respecto a la situación de la mujer esclava en Chile, en el siglo XIX véase el artículo de Rosa Soto Lira Negras esclavas. Las otras mujeres de la colonia. Para una visión amplia del proceso de abolición de la tan desconocida esclavitud en Chile, véase el libro La abolición de la esclavitud en Chile de Guillermo Feliú Cruz.

12 "Plantas medicinales en mapuzungun" (Castillo y Rebolledo 12). 
e histórica se enmarca en una lógica patriarcal, que es necesario examinar. En el patriarcado mapuche vemos que la mujer se inscribe en una seria de oposiciones complementarias (Kalku-Machi; Enfermedad-Salud; Océano-Tierra, entre otras), lo que la sitúa en un lugar móvil (Montecino 10). Pese a esta movilidad y complementariedad en la que se inscribe la mujer, cabe señalar que: "La mujer quedará presa en las tramas que la organización social teje para desarrollar la existencia, y desprovista de bienes y herencia, sólo tendrá su cuerpo reproductor y productor de hijos y bienes" (Id. 15). Que la mujer no tenga bienes y herencia es algo que se trastoca en la novela que examinamos. En ésta se puede apreciar como el espacio del prostíbulo posibilita que las mujeres no sean un elemento a ser tranzado entre familias, al contrario, vemos en el prostíbulo una suerte de paréntesis, en donde se tensionan tanto el patriarcado mapuche, como el wingka. Es importante mantener estas particularidades ya que permiten apreciar y concretizar aún más el entronque patriarcal.

Profundizaremos en torno a la noción de patriarcado para poder evaluar sus alcances, los que no siempre son fáciles de captar. Siguiendo a Rita Laura Segato afirmamos que el patriarcado es la matriz en la que se organiza nuestra sociedad, en la medida en que está regida por una jerarquía de status ligada al género, lo que tiene consecuencias a diversos niveles (Las Estructuras 14). Si bien el patriarcado no escapa a ninguna cultura, su desarrollo no es lineal ni homogéneo:

El patriarcado, nombre que recibe el orden de estatus en el caso del género, es, por lo tanto, una estructura de relaciones entre posiciones jerárquicamente ordenadas que tiene consecuencias en el nivel observable, etnografiable, pero que no se confunde con ese nivel fáctico, ni las consecuencias son lineales, causalmente determinadas o siempre previsibles (Id. 14).

Como señala elocuentemente una cita que funciona como epígrafe en el libro Las estructuras elementales de la violencia: "Ninguna sociedad trata a sus mujeres tan bien como a sus hombres" (55). Al examinar los abordajes de la antropología en relación al género la autora señala que no se pueden negar las estrategias singulares de las mujeres en diversas culturas para tomar posiciones de autoridad, sin embargo, tal como adelanta el epígrafe: "en las más diversas sociedades, la ideología de género, aun presentando diferencias, tiende a representar el lugar de la mujer como un lugar subordinado" (60). Aunque todo orden cultural se estructure en base a una lógica patriarcal, las diferencias entre culturas pueden ser sustanciales respecto a la movilidad de las representaciones en torno al género, las que prescriben ciertas acciones y afectos, promoviendo y facilitando otros. Particularmente, en Desde el fogón... el patriarcado wingka-occidental se entronca con el mapuche promoviendo la hegemonía masculina y heterosexual, prescribiendo roles, afectos, binarizando sexualmente (Butler 99) y naturalizando una forma de propiedad, trabajo y familia. En este patriarcado, las significaciones en relación a lo masculino y lo femenino se rigidizan, haciendo corresponder al primero con el espacio público y al trabajo asalariado; mientras que al segundo es subordinado al primero, quedando relegado a la 
función de reproducción, trabajo doméstico impago u alguna otra actividad con menos privilegio, valía social u económica. Cabe destacar que esa trama que estructura el género no es sencilla ni unidimensional, en realidad son varias los estratos en los que podemos leer los efectos del patriarcado en relación al género y sus jerarquías ${ }^{13}$.

Es por esto que debemos tomar consideración respecto a la lógica patriarcal de la cultura mapuche. Esta forma de estructuración social va a acoplarse, ni lineal, ni homogéneamente, con lo que Federici llama el patriarcado del salario. De esta manera, la lógica patriarcal, de bajo impacto sobre las mujeres, en la que se estructuraba la cultura mapuche viene a generar un 'entronque patriarcal' con el patriarcado del salario, reforzando el lugar secundario de la mujer respecto al hombre, instituyendo así un 'patriarcado moderno de alto impacto', es decir, con efectos de dominación más fuertes sobre las mujeres (Segato, "El sexo" 597). Esta confluencia o entronque patriarcal es visible en la confusión de Rosamaría Treukil Llanka respecto al origen de las normas de género que percibe desde su posición de mujer mapuche:

Tener un marido, reproducir hijos, urdir una familia; nunca supo en qué parlamento se validaron esas medidas; si las trajo el invasor o ya estaban constituidas, y cuando Kintun se quedaba por las noches fuera del hogar, quiso romper las normas mapuche y wingka establecidas, le faltaron fuerzas para rebelarse ante estas doctrinas que desde pequeña le implantaron en su espíritu (52).

Vemos en este pasaje un locus resquebrajado, un espacio en donde se hace patente la diferencia colonial, desde allí surge una pregunta en relación a la influencia del mundo wingka sobre el mapuche.

La noción de patriarcado del salario que elabora Silvia Federici nos permite dar mayor relevancia a la categoría de género en el marco de una crítica feminista a lógica patriarcal y capitalista. Sin embargo, queda una particularidad que se escapa al concepto de 'patriarcado del salario' y a su articulación con la noción de 'entronque patriarcal', esta especificidad tiene relación con el antagonismo con el mundo wignka. Dicho antagonismo ${ }^{14}$

\footnotetext{
${ }^{13}$ Para Rita Laura Segato hay por lo menos cinco niveles en donde tanto el género como el patriarcado se expresan. El estrato cero tiene que ver con la autopercepción biológica y anatómica, en el sentido de macho y hembra, nivel que en realidad nunca examinamos en la medida en que estamos siempre dentro de una cultura. El estrato número uno se representa a través de las categorías de "mujer" y "hombre" que son introyectadas en relación al nivel cero. Un segundo estrato estaría dado por el "género de la personalidad", no necesariamente determinado en base a los previos estratos, se trata de actitudes y temperamentos en relación a las interacciones sociales de una persona dada. El tercer estrato da cuenta de la orientación sexual, la que es mucho más flexible que las categorías de homosexualidad y la heterosexualidad. Un cuarto estrato lo constituye la disposición sexual, la cual da cuenta de la tendencia a asumir roles activos o pasivos en su interacción sexual. El último estrato está relacionado con la división social del trabajo, dimensión que suele asociarse al género, dejando opacada la complejidad de relaciones no lineales entre los estratos anteriormente descritos. (Segato, Las estructuras 77-78).

${ }^{14}$ La noción de 'antagonismo' la tomamos desde el planteamiento de Ernesto Laclau, sin embargo, su articulación con el concepto de extimidad en psicoanálisis la relevamos a partir de la tesis de magíster Laclau contra Laclau
} 
tiene, al parecer, un rasgo de 'extimidad', entendido éste como la imposibilidad de que una identidad o una diferencia esté completamente escindida de lo que considera otro, más bien, esta diferencia identitaria es 'éxtima' (interior y exterior al mismo tiempo), en el sentido lacaniano, en la medida en que aquello permite un cierto cierre identitario, constituyendo así al campo que lo enuncia como algo exterior:

Para el Psicoanálisis la función del pequeño objeto 'à tiene esa doble función tanto positiva como negativa, ya que si bien representa la falta en el campo simbólico es también el tapón, la respuesta o el cierre de esa misma falta. Desde ahí que se señale la 'extimidad' de 'a' como aquello que falta y anuda al mismo tiempo, por ello no está en un afuera, pero tampoco en una interioridad absoluta (Miller 329).

En este sentido, el significante wingka es relevante si buscamos caracterizar la lógica patriarcal presente en la novela, en la medida en que este antagonismo genera una clausura que da forma y límite a lo 'mapuche'.

\section{Hetero wingka patriarcado del Salario}

Concretizando aún más el sistema dominación debemos notar que el patriarcado que pugna por instalarse está ligado al capital, pero también, desde un enfoque de género se lo puede enmarcar como un patriarcado heteronormativo, el cual naturaliza y promueve la unión y lazo social entre una concepción naturalizada y binaria de mujer y hombre ligada a lo biológico, demarcando una zona de indeseabilidad en torno a otras posiciones de género tratadas como anómalas. Tal como señala Judith Butler la noción de heteronormatividad estaría dada por: "Instituir una heterosexualidad obligatoria y naturalizada requiere y reglamenta al género como una relación binaria en la que el término masculino se distingue del femenino, y esta diferenciación se consigue mediante las prácticas del deseo heterosexual" (81). Valeria Silva, activista intersex Mapuche, señala que otras formas de construcción de género eran concebidas en el mundo mapuche como un regalo de la naturaleza. Esto nos da ciertas pistas para comprender la diferencia de régimen que se comienza a consolidar luego de la Ocupación del WallmapulAraucanía (Silva s.p).

A este patriarcado que hemos venido delineando lo podemos caracterizar aún más tomando la noción de Doris Quiñimil, quien acuña el término interseccional ${ }^{15}$ :

de Alejandro Varas (2014), la cual examina dicho concepto a la luz de la teoría lacaniana, haciendo énfasis en las falencias de dicho concepto. Para efectos de nuestro análisis el antagonismo que se manifiesta en relación al mundo wingka es un límite de dos campos heterogéneos, cuya diferencia promueve una confrontación necesaria. Un conflicto frente al cual no basta traducir las demandas de un lado y hacia el otro.

${ }^{15} \mathrm{El}$ concepto de intersecionalidad es un gran aporte conceptual que nace desde el feminismo. Este término da cuenta de la particularidad del funcionamiento del poder de diversas opresiones y cómo estas puede solaparse y potenciarse. Se trata de un concepto necesario para dar cuenta de la particularidad de las luchas y las resistencias 
Heterowingkapatriarcal (9). El apelativo de wingka dentro de esta intersección agrega el significado de ladrón o extraño, que, en el mundo mapuche, designa el carácter particular de otras sociedades que usurparon sus tierras y sus bienes, caracterizando, no sólo esos actos, sino un imaginario más complejo, en relación al largo vínculo colonial, previo al momento en el que transcurre la novela. Dentro de la obra que examinamos al wingka se le define como aquel que: "siempre anda ladiao pa 'un lao; pa 'el lao que más le conviene" (85). Esta búsqueda de conveniencia constituye una tendencia individualista y comercial, en donde todo puede ser comprado, estos valores mercantiles conforman parte del ser wingka. El wingka no sólo sería aquel representante de otra cultura que daña, roba y violenta, sino además el portador de valores contrarios a lo mapuche, como hemos dicho lo wingka traza un antagonismo y sostiene un lazo éxtimo en la medida en que:

no es el enemigo externo el me impide alcanzar la identidad conmigo mismo, sino que cada identidad, librada a sí misma, está ya bloqueada, marcada por una imposibilidad, y el enemigo externo es simplemente la pequeńa pieza, el resto de realidad sobre el que "proyectamos» o «externalizamos» (Žižek 171-2).

De esta manera este adjetivo separa aguas entre las dos culturas, marcando desde la perspectiva mapuche un límite y diferencia interna que promueve una confrontación constante. Este significante condensa dentro de sí varias características, las que guardan relación con la violencia, el despojo de las tierras y la inconsciencia e inmoralidad que portan estos sujetos. Wingka es también dentro de la novela los chilenos y chilenas. En boca de los personajes este adjetivo parece irreductible, marcando un antagonismo radical o puro entre las dos culturas. Para Žižek el antagonismo radical está dado por la propia imposibilidad de cerrar una identidad, el antagonismo permitiría colocar afuera una diferencia que es interior y que es fundante del sujeto o de la colectividad en este caso: "de lo que se trata es del hecho de que la negatividad del otro que me impide alcanzar la plena identidad conmigo mismo es solo una externalización de mi autonegatividad, de mi auto-obstaculización respecto de mí mismo" (172). Por eso, más arriba tomamos la noción de 'extimidad' para dar cuenta de esta doble vinculación de la falta ('a’). Este marco teórico nos permite comprender la identidad mapuche desde un paradigma político posfundacional, en donde las identidades no están arraigadas o fundadas en algo natural, biológico o algo dado, sino que se trata de articulación e imaginarios contingentes que entran en disputa. El antagonismo con lo wingka también da cuenta de esas complicidades, alianzas e intercambios que datan de la colonia, por ello lo wingka podría ser leído como una categoría que muestra los diversos antagonismos en el seno mismo de las comunidades mapuche, como en el caso de la "Potoquina" cuyo: "espíritu nadó entre dos aguas y hacia ninguna orilla se aferraba" (99). Este antagonismo 'éxtimo' es visible en la historiografía:

en diversos ámbitos. Dicho concepto ha tenido una gran trayectoria desde que nace en la esfera jurídica con el fin de volver inteligible la articulación de opresiones y dominaciones entre, por ejemplo, clase, género, etnia, entre otras (M. La Barbera 106). 
Así, encontramos a la sociedad mapuche del Fütawillimapu, antes de la intromisión del winka, dividida por conflictos internos, no por razones externas, sino por su propia dinámica social, esta división será la que permitirá que en el Fütawillimapu pueda entrar el winka (Cárcamo 177).

Esto tiene otro correlato histórico, donde diversas autoridades mapuches han generado diversas alianzas con el mundo wingka, vínculos que han sido expresados en el travestismo de varios líderes mapuche ${ }^{16}$. En particular, en el contexto de la novela se aprecia el antagonismo y la diferencia con el wingka el cual es una mezcla de elementos entre lo colonial español y lo chileno:

Siendo chicuela, un caminero chileno me dijo: india de mierda. Le contesté: ¡Y tú, hijo de puta revuelta con ladrón!... Me pegó y, me defendí con todo lo que encontré a mi paso. Desde ese día... Cuando los chilenos hablan de sus abuelos... ¡Tan güeones los chilenos, todos tienen abuelos españoles! Yo me paraba ante ellos y le preguntaba: ¿¿De qué cárcel vino tu abuelo? (79).

Este conflicto permanente es una de las razones por las cuales se les prohíbe el ingreso a chilenos al prostíbulo: "PPorque al chileno una güeva le pesa quince y la otra le pesa veinte!” (85). La lógica patriarcal que se entronca entonces es una sumatoria de elementos que se interseccionan, lo que, tomando lo que hemos desarrollado hasta el momento, podría ser definido como: heterowingka patriarcado del salario.

El llegar a ser chilena, chileno o wingka es vivido como una amenaza latente, esta influencia se ve con recelo por parte de la Pincoya: "Y lo que más me preocupa es que mis hermanos con el tiempo caminen igual [en relación a que los chilenos y chilenas buscan su interés personal]" (85). Ser wingka o chileno es traer una cierta política y religión, elementos que son vistos con recelo por la Pincoya y Kintun, ambos comparten la idea de que tanto la política como la religión eran elementos que les habían tirados sobre las mentes (86). Ambas instituciones ligadas íntimamente a la noción de wingka son percibidos como una amenaza de la cultura mapuche, este temor podría resumirse en no llegar a ser: "un indio trasplantado de hombre blanco con su quebrantada alma de chileno" (92). Frente a esta presión del mundo wingka, hay quienes también añoran su forma de vida, no encontrando satisfacción o resguardo económico y social suficiente en el prostíbulo: "Una de las prostitutas que llamaban Culítica de forma autodidacta aprendió a leer y a escribir para luego tener una pulpería (almacén) y no volver al Cabaret" (97). La lógica que trae consigo el 'heterowingka

\footnotetext{
${ }^{16}$ En un trabajo que examina la relación antropológica entre lo wingka y lo mapuche, se señala lo siguiente a raíz del travestismo de diversas figuras políticas mapuche a lo largo de la historia: "El devenir implica una configuración siempre singular y que afecta a ambos términos. Parafraseando a los autores de esta noción de devenir, un cacique no puede devenir general sin que el general devenga él mismo otra cosa." (Foerster y Menard 37).
} 
patriarcado del salario' no es homogéneamente percibida, aceptada y asimilada, dentro de quienes transitan y se quedan en "La trompa de pato".

Finalmente, la influencia de lo wingka es tan potente y sostenida que una vez que la hija de la Pincoya (Pinconyita) se hace cargo del prostíbulo luego de la muerte de su madre, todos los elementos indígenas comienzan a quedar soterrados: "después de aproximadas siete décadas sucumbió ante la invasión, perdiéndose para siempre la mística y el olor a pueblo originarios que a los hombres atrapó, una nueva clientela y putas wingka fue la maldición" (87). Tanto la nueva clientela, como la llegada de putas wingka, marcan el paso de "La trompa de pato" como espacio de transición entre el resurgimiento de la acumulación originaria y la consolidación 'heterowingka patriarcado del salario' que parece finalmente imponerse.

\section{OpOSICIONES y SUBVERSIONES:}

A pesar de lo entramado que se encuentran los dispositivos estatales, económicos y religiosos y de género que se confrontan e imbrican con el imaginario mapuche, vemos en este campo de disputa varias subversiones y oposiciones. Por subversiones comprendemos prácticas y discursos que vienen a transgredir, a reconfigurar un entramado de poder, es lo que vemos en el travestismo que utilizan algunas mujeres mapuche al devenir chiñura y el mismo funcionamiento del prostíbulo en el contexto del entronque patriarcal que hemos descrito. Estas subversiones y oposiciones surgen de una apropiación de los términos, modos y prácticas con el fin de lograr otro objetivo, generando una acción deliberada que modifica o, al menos, tensiona los códigos:

Si la subversión es posible, se efectuará desde dentro de los términos de la ley, mediante las opciones que aparecen cuando la ley se vuelve contra sí misma y produce permutaciones inesperadas de sí misma. Entonces, el cuerpo culturalmente construido se emancipará, no hacia su pasado $<<$ natural $>>$ ni sus placeres originales, sino hacia un futuro abierto de posibilidades culturales (Butler 196).

Optamos por la noción de subversión de Judith Butler en la medida en que nos permite comprender, de manera más precisa, cómo se configura y reconfigura el entronque patriarcal. Esta noción nos brinda una óptica inmanente del poder, donde éste no es sólo dominación desde un lugar hacia otro o desde un sujeto sobre otro, sino que se configura en las mediaciones y relaciones tanto a nivel macropolítico, micro-mesopolítico y micropolítico. ${ }^{17}$ El concepto de subversión nos permite valorar y sopesar acciones, gestos

${ }^{17}$ Utilizamos estos tres niveles tomando algunas aportaciones de las teorías críticas en torno a educación. Aludimos con estos tres niveles a tres estratos que interactúan entre sí, en el macro-político podríamos señalar al Estado, en lo micro-meso-político al prostíbulo y en lo micro-político la interacción, por ejemplo, entre la Pincoya y la Pincoyita (Terrén). 
y estrategias sutiles que tiene un papel relevante en la novela. Desde allí señalamos que la forma particular de organización dentro del prostíbulo genera oposiciones y subversiones ${ }^{18} \mathrm{a}$ la organización patriarcal hegemónica de la sociedad wingka chilena y capitalista, expresada en la noción de 'hetetowingka patriarcado del salario'. Pero también se generan subversiones al orden patriarcal mapuche-williche, recordemos que en la organización de este grupo las malocas o conflictos entre familias, tenían el objetivo fundamental de obtener ganado y mujeres. La subordinación de las mujeres mapuche se evidencia en el rapto y violación que sufrían cuando un hombre quería casarse con ellas, como aparece en Katrilef, otra Novela de Graciela Huinao. ${ }^{19}$ Desde allí, es lícito afirmar que el prostíbulo y la relativa autonomía de las mujeres en él tensione ambos bloques patriarcales que se anudan.

Si bien a primera vista hemos dicho que en "La trompa de pato" se dan una serie de resistencias frente a los procesos estructurales que hemos descritos, esto puede ser matizado, ya que las acciones que de forma inmediata se podrían interpretar como resistencias, en realidad se pueden situar en un nivel semejante a las nociones de oposición y subversión. Creemos que en la novela no figuran resistencias al entronque patriarcal, en el sentido en que Henry Giroux concibe la resistencia:

[S]e debe subrayar enérgicamente que el valor esencial de la noción de resistencia tiene que ser medido no sólo por el grado en que promueve el pensamiento crítico y la acción reflexiva sino, de manera más importante, por el grado en el que contiene la posibilidades de estimular la lucha política colectiva alrededor de problemas de poder y determinación social (Giroux 148).

Es difícil vislumbrar un proyecto alternativo, sí quizá un horizonte, dentro de lo que acontece dentro de la obra. El prostíbulo parecer ser un espacio de transición y de negociación de significados, un espacio fronterizo en donde las mixturas culturales permiten la permanencia del imaginario social mapuche. Una acción que deja entrever tenuemente

\footnotetext{
${ }^{18}$ Henry Giroux entiende por resistencia una postura, modelo o proyecto que promueva una visión alternativa, a diferencia de una oposición que queda en el nivel de una confrontación o una acción más bien aislada y que debe ser examinada en miras de sopesar sus posibilidades críticas (Giroux 147-8). Otra concepción desde la cual se nutre la teoría de Giroux es la de Foucault, éste señala en el primer volumen de la Historia de la Sexualidad que donde "hay poder hay resistencia" (116) y que ésta no es exterior al poder, sino que se da de forma inmanente. Si bien estamos de acuerdo con esta afirmación, creemos que la forma en que Gyroux concibe la resistencia nos permite otorgarle una especificidad histórica y política al concepto. Es importante señalar esto en la medida en que clarifica algunas preguntas sencillas pero relevantes ¿cómo diferenciar las resistencias? ¿Todo acto que se desvía de la norma es una resistencia? ¿Bajo qué principios una resistencia o varias resistencias se articulan y qué debe suceder para una disputa de mayor envergadura?

${ }^{19}$ En esta novela se coloca énfasis en la constricción que genera el matrimonio, siendo la mujer tratada como si fuese un ser-objeto: "Las leyes de su pueblo decían que ella debía pasar una noche "de prueba": ensayo que todas las mujeres temían, ya que si el comprador no estaba contento con el producto, poseía la facultad de devolverla tras su uso, argumentando su descontento carnal y nadie ponía en tela de juicio la palabra de un hombre insatisfecho" (38).
} 
una posibilidad de transformación o de lucha política colectiva es la de un rayado en una de las paredes del barrio "Un pueblo sin bandera, es un pueblo sin guerra" (14). Dicho rayado no generó mayor impacto, salvo el de catalogar a quien lo realizó como un "Indio, revolucionario, poeta, brujo y loco" (15). Esta irrupción de la posibilidad de articulación política queda como un elemento minoritario dentro del entramado de la novela. Los intereses que movilizan a la mayor parte de los personajes se encuentran vinculados con objetivos inmediatos y con formas de sobrevivir al escenario que se les presenta, no emerge un discurso de pueblo o de comunidad con proyecciones o una crítica estructural (como la podemos ver dentro de las luchas políticas actuales de los movimientos mapuche), más bien las leemos como artimańas, estrategias, alegrías y gritos de dolor aislados en el medio del desmantelamiento de una cultura.

\section{Obras CiTADAS}

Aniñir, David. 2009. Mapurbe, venganza a raiz. Santiago de Chile: Pehuén Editores.

Butler, Judith. 2017. El género en disputa. El feminismo y la subversión de la identidad. Editorial Antítesis.

Cárcamo, Alejandro. 2015. «Conquista e invasión a la sociedad mapuche-williche. El establecimiento de un nuevo poder colonial en el Futawillimapu (1750-1830).» Historia 2.0. Conocimiento histórico en Clave Digital: 171-187.

Carrasco, Iván. 2014. «La construcción de la literatura mapuche.» Revista canadiense de estudios hispánicos 39.1: 105-121.

Castillo Caripán, Millaray y Camila Ramírez Rebolledo. 2017. Violencia estatal contra la mujer mapuche. Tesis Universidad de Chile: Santiago de Chile, Digital.

Falabella, Soledad, Graciela Huinao y Roxana Miranda Rupailaf. 2009. Hilando en la memoria. Santiago: Editorial Cuarto Propio. Medio impreso.

Federici, Silvia. 2010. Calibán y la bruja. Mujeres, cuerpo y cumulación originaria. Madrid: Traficantes de sueños.

Feliú, Guillermo. 1973. La abolición de la esclavitud en Chile. Santiago: Editorial Universitaria.

Figueroa, Damsi. 2018. «El humor en la narrativa de Graciela Huinao.» Acta Literaria: 91110 .

Foerster, R y A Menard. 2009. «FUTATROKIKELU: DON Y AUTORIDAD EN LA RELACIÓN MAPUCHE-WINGKA.»Atenea: 33-59.

Foucault, Michel. 2007. Historia de la sexualidad. 1- la voluntad de saber. México, D.F.: Siglo XXI.

Giroux, Henry. 2004. Teoría y resistencia en educación. Una pedagogía para la oposición. México, D.F.: Siglo veintiuno editores.

Guerra, Lucía. 2014. La ciudad ajena: Subjetividades de origen mapuche en el espacio urbano. Santiago de Chile: Ceibo Ediciones. 
Huinao, Graciela. 2010. Desde el fogón de una casa de putas williche. Osorno: Caballo de Mar.

. 2014. La nieta del brujo. Seis relatos Williche. Lampa: Ediciones Caballo de Mar. . 2015. Katrilef. Hija de un ülmen williche. Santiago de Chile: ICIIS.

La Barbera, Maria Caterina. «Interseccionalidad, un "concepto viajero": orígenes, desarrollo e implementación en la Unión Europea.» Interdisciplina 4.8 (2016): 105-122.

García Barrera, Mabel, Hugo Carrasco Muñoz y Verónica Contreras Hauser. 2005. Crítica Situada. El estado actual del arte y la poesía Mapuche. Rakizuam. Pu mapuce tañi kimon ka tañi vl zugu fahtepu. Ed. Mabel García Barrera. Temuco: Editorial Florencia. Material impreso.

Marx, Karl. 2009. El capital. Libro primero. El proceso de producción del capital. Ed. Pedro Scaron. Vol. 3. México D.F: Siglo XXI editores.

Millaguir, Ruth. 2008. Cherrufe. La Bola de Fuego. Valdivia: Grupourbe.

Miller, Jacques-Alain. 2010. Extimidad. Los cursos psicoanaliticos de Jacques-Alain Miller. Buenos Aires: Paidós.

Montecino, Sonia. 1995. Sol viejo, Sol vieja. Lo femenino en las representaciones mapuche. Santiago de -chile: CEDEM.

Oyewúmi, O. 1997. The invention of women. Making an African sense of wester gender discourses. Minneapolis: University of Minnesota Press.

Pichinao, Jimena Huenchuleo. 2015. «La mercantilización del mapuche mapu. Hacia la expoliación absoluta.» AWÜKAN KA KUXANKAN. Violencias coloniales en Wajmapu. Ed. Enrique Antileo Baeza, y otros. Temuco: Comunidad de Historia Mapuche. 87-105.

Quiñimil, Doris. 2012. «PETU MONGENLEINÑ, PETU MAPUCHENGEN. Todavía estamos vivxs, todavía somos mapuche.» Universidad de Granada. Digital. 9 de marzo de 2018. <http://digibug.ugr.es/bitstream/10481/22726/1/DORIS QUI\%C3\%91IMIL_TFM_\%202012_lastversion.pdf>.

Rama, Angel. 2004. La ciudad letrada. Santiago: Tajamar Editores,

Segato, Rita Laura. 2014. «El sexo y la norma: frente estatal, patriarcado, desposesión, colonialidad.» Estudos Feministas, Florianópolis: 593-616. . 2003. Las estructuras elementales de la violencia. Ensayos sobre género entre la antropología, el psicoanálisis y los derechos humanos. Buenos Aires: Universidad Nacional de Quilmes.

Silva, Valeria. 2017. "Valeria Silva, Activista intersex Mapuche: "Antiguamente una persona intersex se consideraba un regalo de la naturaleza”.» POUSTA. Marcial Parraguez.. Web. 16 de Marzo de 2018. <https://pousta.com/valeria-silva-activismo-intersexmapuche/\#>.

Soto, Rosa. 1992. «Negras esclavas. Las otras mujeres de la Colonia.» Proposiciones: 21-31.

Terrén, Eduardo. 2004. «Las organizaciones educativas como sistemas de comunicación. Un enfoque micropolítico.» Revista iberoamericana de educación: 189-214.

Žižek, Slavoj. 2000. «Más allá del análisis del discurso.» El reverso de la diferencia. Identidad y politica. Ed. B Arditi. Caracas: Nuea Sociedad. 169-179. 